\title{
Components of activity and sleep in two species of chipmunks: Tamias striatus and Eutamias dorsalis
}

\author{
D. Q. ESTEP, E. L. CANNEY, C. G. COCHRAN \\ and J. L. HUNTER \\ University of Georgia, Athens, Georgia 30602
}

\begin{abstract}
Components of activity and sleep were observed for 12 wild trapped Tamias striatus and 12 wild trapped Eutamias dorsalis under laboratory conditions. The animals were housed individually in clear plastic cages and observed continuously for $24 \mathrm{~h}$. The behavior of each animal was recorded at 1-min intervals and classified into one of six mutually exclusive categories: locomotor-explore, groom, eat, drink, quiet inactive, or sleep. Both species were found to be predominantly day active. Significant species differences were found in the proportions of time spent grooming and quietly inactive, while significant sex differences were found in time spent eating. Species differences were also found in the circadian placement of all categories except quiet inactivity. The chipmunks were similar in the components of their activity to laboratory rats and similar in their sleep to other mammals that sleep in safe sleep spots.
\end{abstract}

A variety of field and laboratory investigations have reported that chipmunks are diurnal in their activity (Allen, 1938; De Coursey, 1972; Gordon, 1943; Kavanau, 1969). However, as Bindra (1961) has pointed out, general or spontaneous activity is made up of a number of components, such as walking, grooming, and eating, and there has been little quantitative description or analysis of these components. While it may be true that all chipmunks are diurnal in their general activity, important species differences could exist among them with respect to the components of activity or in the patterning of these components throughout the circadian cycle.

The present report presents the first quantitative description of activity and sleep for two species of chipmunks, the eastern chipmunk, Tamias striatus and the cliff chipmunk, Eutamias dorsalis. Both species are small, ground-dwelling members of the family Sciuridae. Eastern chipmunks are common to the deciduous forests of eastern North America (Allen, 1938), while cliff chipmunks are common to rocky, coniferous forests in the southwestern United States (Gordon, 1943).

\section{METHOD}

\section{Subjects}

The subjects were six male and six female Tamias striatus trapped within the city limits of Athens, Georgia, and six male

This study was supported by a grant from the University of Georgia Office of the Vice President for Research. We wish to thank J. R. Callahan for providing the Eutamias and T. Puente, R. B. Fischer, and B. N. Bunnell for assistance with various aspects of the study. Requests for reprints should be directed to D. Q. Estep, Department of Psychology, University of Georgia, Athens, Georgia 30602. and six female Eutamias dorsalis trapped in the Santa Catalina mountains, $50 \mathrm{~km}$ from Tucson, Arizona. The Tamias ranged in weight from 98.3 to $145.8 \mathrm{~g}(\mathrm{M}=122.0)$, while the Eutamias ranged in weight from 60.0 to $74.8 \mathrm{~g}(\mathrm{M}=67.5)$. All of the animals had been in the laboratory from 3 to 9 months at the time of the observations and appeared to be sexually mature.

Chipmunks were housed and tested in isolation in clear plastic cages measuring $29 \times 19 \times 13 \mathrm{~cm}$. San-i-cel bedding material covered the bottoms of the cages and Purina laboratory chow, sunflower seeds, and water were available ad lib. The colony was maintained in an air-conditioned room on a 14-hlight, 10-h-dark cycle with light onset at $1930 \mathrm{~h}$.

\section{Apparatus}

The animals were observed in their home cages. Data were collected by hand with check sheets.

\section{Procedure}

Three days prior to the start of observations, the animals in their home cages were moved from the colony room to a small room and placed on a table facing a one-way mirror. The testing room was maintained on the same light-dark cycle as the colony room, with lighting during the light phase supplied by two white fluorescent tubes and four $25-\mathrm{W}$ red incandescent bulbs. This produced 42-62 fc of illumination (452.1-667.4 lx) in the cages during the light phase. During the dark phase, 2-3 fc of illumination (21.5-32.3 lx) were provided by four $25-\mathrm{W}$ red bulbs. A white-noise generator operated during observations to mask sudden noises.

The observers sat in a room on the other side of the one-way mirror and collected the data using an instantaneous sampling technique (Altmann, 1974). Each animal was scanned once per minute for 24 consecutive hours, and the ongoing behavior was categorized into one of six mutually exclusive categories: locomotorexplore, groom, eat, drink, quiet inactive, or sleep. Sleep was defined as behavioral quiescence accompanied by closure of the eyelids; quiet inactive was behavioral quiescence with the eyes open; drink was licking movements at the water tube; eat was chewing or manipulating food objects; groom was scratching, licking, or manipulation of the body; and locomotorexplore was walking, jumping, sniffing, and other movements not covered by other categories. 


\section{RESULTS}

A comparison of the instantaneous sampling method with actual durations of behavior was made for two randomly chosen animals over a total of $4 \mathrm{~h}$ subsequent to the main observations of the experiment. This comparison revealed that the instantaneous sampling method provided very accurate estimates of hourly totals of all categories except drink.

Percentage agreement between the sampling technique and actual hourly totals for each category was: locomotor-explore, 96\%; groom, 90\%; eat, 94\%; sleep, $99 \%$; quiet inactive, $76 \%$; and drink, $46 \%$. Drinking was a very rare event and accounted for much less than $1 \%$ of the total time. As a result, drink was eliminated from further separate analysis. Interobserver reliability based on percentage agreement of observations for two animals for $2 \mathrm{~h}$ was $91 \%$.

Table 1 presents the mean percentage of time spent in the various components of activity and sleep for males and females of both species. The category of general activity was derived by summing the total percentages for the categories eat, drink, groom, and locomotorexplore and calculating a mean for each group. This category was created because it was felt that it most accurately reflected the general activity commonly observed in laboratory and field.

The data of Table 1 indicate that both species of chipmunks spent the majority of their time in behavioral sleep (62\% for Eutamias, 68\% for Tamias). The categories groom, eat, and quiet inactive occurred rather infrequently, each accounting for less than $10 \%$ of the total time. Locomotor-explore accounted for less than $24 \%$ of the time for all groups.

Analyses of variance were performed on each of the categories in Table 1 . The analyses revealed no significant species or sex differences in the percentages of time devoted to general activity, locomotor-explore, or sleep. A significant species difference was revealed for groom $[\mathrm{F}(1,20)=5.37, \mathrm{p}<.05]$, with the Eutamias grooming more than the Tamias, and a significant sex difference was found for eat $[F(1,20)=4.72, p<.05]$, with females eating more than the males. Significant species $[F(1,20)=5.88, p<.05]$ and Species by Sex

Table 1

Percent of Time Spent in Six Categories of Behavior for Males and Females of Both Species

\begin{tabular}{|c|c|c|c|c|c|c|c|c|}
\hline \multirow{3}{*}{$\begin{array}{l}\text { Behavioral } \\
\text { Category }\end{array}$} & \multicolumn{4}{|c|}{ Eutamias } & \multicolumn{4}{|c|}{ Tamias } \\
\hline & \multicolumn{2}{|c|}{ Females } & \multicolumn{2}{|c|}{ Males } & \multicolumn{2}{|c|}{ Females } & \multicolumn{2}{|c|}{ Males } \\
\hline & Mean & SE & Mean & SE & Mean & SE & Mean & SE \\
\hline General Activity & 35.7 & 2.6 & 30.2 & 6.7 & 23.9 & 3.4 & 23.8 & 3.9 \\
\hline Locomotor-Explore & 23.6 & 1.7 & 19.1 & 7.1 & 12.4 & 3.5 & 14.8 & 4.3 \\
\hline Groom & 7.5 & 1.3 & 7.4 & 1.1 & 5.4 & .8 & 5.0 & .4 \\
\hline Eat & 4.4 & .6 & 3.7 & .2 & 5.7 & .7 & 4.2 & .4 \\
\hline Quiet Inactive & 4.0 & .7 & 6.1 & 1.4 & 10.3 & 1.9 & 5.6 & .8 \\
\hline Sleep & 60.4 & 2.1 & 63.7 & 7.6 & 65.8 & 2.9 & 70.3 & 3.9 \\
\hline
\end{tabular}

Note-Data are presented as means and standard errors (SE).
Table 2

Log-Transformed Diurnal Ratios for Six Categories of Behavior for Eutamias and Tamias

\begin{tabular}{lrrrrr}
\hline \multirow{2}{*}{$\begin{array}{c}\text { Behavioral } \\
\text { Category }\end{array}$} & \multicolumn{2}{c}{ Eutamias } & & \multicolumn{2}{c}{ Tamias } \\
\cline { 2 - 3 } \cline { 6 - 7 } \cline { 5 - 6 } & Mean & SE & & Mean & SE \\
\hline General Activity & .976 & .122 & & .373 & .078 \\
Locomotor-Explore & 1.240 & .200 & & .501 & .136 \\
Groom & .738 & .151 & & .084 & .072 \\
Eat & .832 & .134 & & .383 & .096 \\
Quiet Inactive & .342 & .157 & & .467 & .113 \\
Inactive Sleep & -.186 & .062 & & .036 & .021 \\
\hline
\end{tabular}

Note-Data are presented as means and standard errors (SE).

interaction effects $[F(1,20)=6.59, p<.05]$ were found for the category quiet inactive. A Newman-Keuls test revealed that the interaction was entirely due to differences between the Tamias and Eutamias females $(p<.05)$. There were no significant differences between the males.

In addition to calculating the percentage of time devoted to various categories of behavior, a measure of the circadian patterning of each category was also calculated. This measure, the diurnal ratio, was calculated by dividing total time spent in the light by the total time spent in the dark for each category. These ratios were found to be highly positively skewed and in order to meet the assumption of normality required by the analysis of variance, the diumal ratios were transformed by calculating the natural log of each score, as suggested by Winer $(1971$, p. 400$)$.

The log-transformed diurnal ratios are presented in Table 2. These ratios can take values from $-\infty$ to $+\infty$, with values less than .146 indicating a predominantly nocturnal occurrence of the behavior and values greater than .146 indicating a predominantly diurnal occurrence of the behavior. All of the categories presented in Table 2, with the exception of groom in Tamias and sleep in both species, are predominantly diurnal. Analysis of variance performed on the transformed diurnal ratios showed the Eutamias to be significantly more diurnal than the Tamias for the categories general activity, locomotor-explore, groom, and eat, and significantly more nocturnal for sleep [general activity, $\mathrm{F}(1,20)=17.93, \mathrm{p}<.001$; locomotor-explore, $\mathrm{F}(1,20)=$ $9.02, \mathrm{p}<.01$; groom, $\mathrm{F}(1,20)=16.06, \mathrm{p}<.001$; eat, $F(1,20)=7.82, p<.025$; sleep, $F(1,20)=11.64$, $\mathrm{p}<.005]$.

Figures 1 and 2 illustrate in a graphic fashion the species differences found in the patterning of activity and sleep. Figure 1 shows the number of minutes per hour devoted to general activity in both species. Figure 2 presents similar data for sleep. Figure 1 shows the Eutamias to be clearly more diurnal in their general activity than the Tamias. It is also of interest to note the increase in activity $2-3 \mathrm{~h}$ prior to light onset in both species. The sleep patterns seen in Figure 2 show almost a mirror image of the general activity patterns, with the Eutamias more nocturnal in their sleep than the Tamias. 


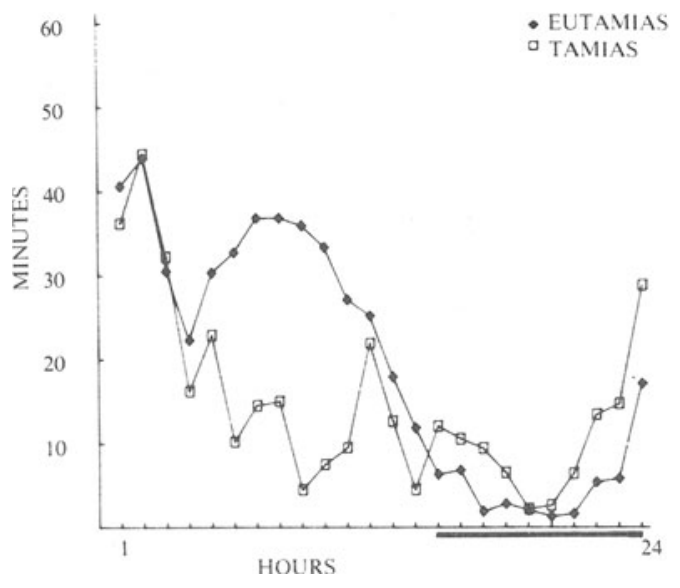

Figure 1. Minutes per hour spent in general activity by two species of chipmunks. Hours of darkness are indicated by the dark bar.

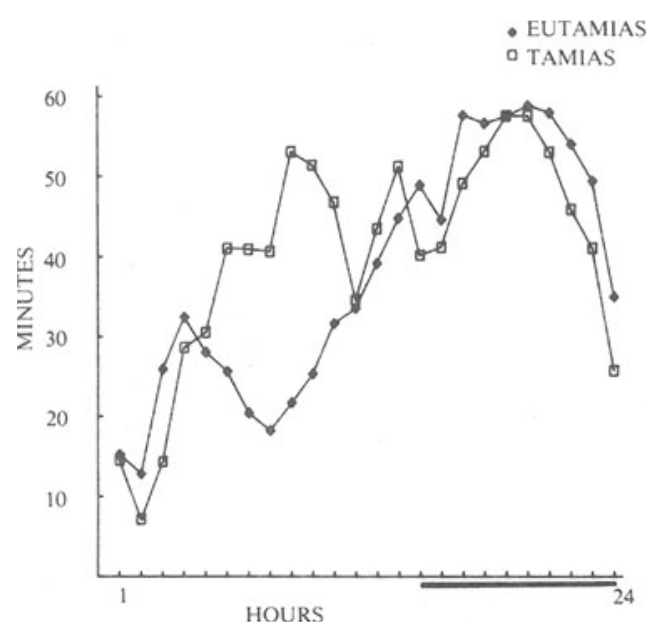

Figure 2. Minutes per hour spent in sleep by two species of chipmunks. Hours of darkness are indicated by the dark bar.

\section{DISCUSSION}

The present results support previous reports that both Tamias striatus and Eutamias dorsalis are principally diurnal in their activity. However, they also show a significant species difference in the proportion of time spent grooming, and significant differences between the females of both species in quiet inactivity. Significant species differences were found in the circadian patterning of all categories of behavior except quiet inactive. Females of both species were also found to devote a greater proportion of their time to eating than did males. The significance of these differences is not clear at this time.

The sex difference in eating was not related to sex differences in weights of the animals, as there were no significant differences in the weights of males and females $(M=95.6 \mathrm{~g}$ for males, $\mathrm{M}=93.9 \mathrm{~g}$ for females). The species differences do not appear to correlate in any simple way with known differences in ecology or natural history of these two species.

There was an observed increase in activity during the dark phase 2-3 h before light onset in both species. Both De Coursey (1972) and Kavanau (1969) have observed similar nocturnal activity in laboratory studies of Tamias, but Kavanau attributes this to the use of low illumination levels (less than $40 \mathrm{fc}$, $430.6 \mathrm{~lx}$ ) during the light phase. He reports Tamias to be $98 \%$ active when the illumination in the light phase is $300-3,000$ fc $(3,229.2-32,291.7 \mathrm{~lx})$. Thus, the anticipation of light oriset in the present study may be due to artificially low illumination levels. However, Gordon (1943) and Hart (1976) report species of Eutamias to be active an hour or more before sunrise in the wild. More extensive observations under more natural conditions should be made to determine if this effect is indeed a laboratory artifact.

The percentages of time spent in various categories of behavior for chipmunks are similar in many ways to the percentages reported for male laboratory rats studied under similar conditions (Bolles, 1963). The only large discrepancy appears in the category grooming, where laboratory rats devote two to three times more time to this activity than do chipmunks. Bolles presents no data on circadian placement of behavior in laboratory rats, so comparisons for this parameter are not possible.

The percentages of time devoted to sleeping are similar to those reported for a variety of rodents (Van Twyver, 1969). The present data are also consistent with the hypothesis of Allison and Van Twyver (1970) that total sleep time is a function of the safety of the sleep spot. Thus, they find that burrowing animals like Syrian golden hamsters and 13-lined ground squirrels sleep close to $60 \%$ of the time, while cattle, sheep, and horses-species that sleep in open, unprotected areas-sleep less than $30 \%$ of the time. Both species of chipmunks studied here are known to sleep in subterranian burrows (Allen, 1938; Gordon, 1943) and, as predicted, both species sleep more than $60 \%$ of the time.

The results of the present study illustrate the importance of quantitative descriptions of the components of general activity in comparative studies of activity. A comparison of general activity alone, for example, would not have revealed the significant species differences observed in the proportion of time spent grooming. In fact, the present data in conjunction with the report on laboratory rats suggest that significant species differences may exist among several rodent species in this behavior. Clearly, further work in more natural situations is needed to illuminate the functional significance of the differences found here. Nevertheless, component analysis has proven to be of value in illuminating species differences that would not be revealed by studies of general activity alone.

\section{REFERENCES}

Allen, E. G. The habits and life history of the eastern chipmunk (Tamias striatus lysteri). New York State Museum Bulletin, No. 314, 1938.

Allison, T., \& Van Twrver, H. The evolution of sleep. Natural History, 1970, 79, 56-65.

Altmann, J. Observational study of behavior: Sampling methods. Behaviour, 1974, 49, 227-267.

BINDRA, D. Components of general activity and the analysis of behavior. Psychological Review, 1961, 68, 205-215.

Bolles, R. C. Effects of food deprivation upon the rat's behavior in its home cage. Journal of Comparative and Physiological Psychology, 1963, 56, 456-460.

De Coursey, P. J. LD ratios and the entrainment of circadian activity in a nocturnal and diurnal rodent. Journal of Comparative Physiology, 1972, 78, 221-235.

Gordon, K. The natural history and behavior of the western chipmunk and the mantled ground squirrel. Oregon State Monographs, Studies in Zoology, No. 5, 1943.

HART, E. B. Life history notes on the cliff chipmunk, Eutamias dorsalis, in Utah. Southwestern Naturalist, 1976, 21, 234-246.

KaVANAU, J. L. Influences of light on activity of small mammals. Ecology, 1969, 50, 548-557.

VAN TwYVER, H. Sleep patterns of five rodent species. Physiology \& Behavior, 1969, 4, 901.905.

WINER, B. J. Statistical principles in experimental design, 2nd ed. New York: McGraw-Hill, 1971.

(Received for publication July 12, 1978.) 